\title{
Repairing the lungs one breath at a time: How dedicated or facultative are you?
}

\author{
John P. Leach and Edward E. Morrisey \\ Department of Medicine, Department of Cell and Developmental Biology, Penn Center for Pulmonary Biology, Penn \\ Cardiovascular Institute, Penn Institute for Regenerative Medicine, University of Pennsylvania Perelman School of Medicine, \\ Philadelphia, Pennsylvania 19104, USA
}

\begin{abstract}
Tissue regeneration involves various types of cellular and molecular responses depending on the type of tissue and the injury or disease that is inflicted. While many tissues contain dedicated stem/progenitor cell lineages, many others contain cells that, during homeostasis, are considered physiologically functional and fully differentiated but, after injury or in disease states, exhibit stem/progenitor-like activity. Recent identification of subsets of defined cell types as facultative stem/progenitor cells has led to a re-examination of how certain tissues respond to injury to mount a regenerative response. In this review, we focus on lung regeneration to explore the importance of facultative regeneration controlled by functional and differentiated cell lineages as well as how they are positioned and regulated by distinct tissue niches. Additionally, we discuss the molecular signals to which cells respond in their differentiated state during homeostasis and those signals that promote effective regeneration of damaged or lost cells and structures after injury.
\end{abstract}

Tissues in adult vertebrates exhibit a broad range of reparative capabilities. Understanding the degree to which a tissue can regenerate and how that regenerative process proceeds is necessary to the rational design of future regenerative therapies. Stimulation of endogenous regeneration could be less invasive and more economical than current treatment options for organ failure (Cossu et al. 2018; Wells and Watt 2018). By studying regenerative processes across species, we have begun to discover the cellular, molecular, and genetic mechanisms of regeneration. In particular, lower vertebrates such as fish and amphibians have an enormous capacity for tissue regeneration that involves distinct mechanisms, including dedicated stem/progenitor cell lineages and specific tissue-remodeling processes such as the blastema (Chen and Poss 2017). The formation of a blastema and related processes result in generation of a heterogeneous collection of proliferating cells with restricted cell fates that

[Keywords: development; epithelium; lung; mesenchyme; regeneration] Corresponding author: emorrise@pennmedicine.upenn.edu Article is online at http://www.genesdev.org/cgi/doi/10.1101/gad.319418. 118 . can regenerate entire compartments of an organism, such as limbs, which include blood vessels, bone, and muscle (Chen and Poss 2017).

In mammals, only a subset of organs contains dedicated stem/progenitor cells capable of multilineage renewal. The hematopoietic system, skin, skeletal muscle, and gastrointestinal tract are examples of tissues that have welldescribed and dedicated stem cell lineages essential for both homeostatic maintenance and tissue regeneration (Crane et al. 2017). These stem/progenitor cells are often found within distinct tissue niches and include a variety of cell types, such as mesenchymal support cells, vascular endothelial cells, and immune-modulating cells. A different subset of organs in mammals exhibits either a poor or unknown capacity for regeneration, including the brain and the heart. After injury, such tissues generally form a fibrotic scar to retain architectural integrity. Between the spectrum of these two polar opposite tissue types exist a large number of other tissues, which exhibit a significant level of repair and regeneration but lack a single wellcharacterized and dedicated stem cell population essential for either in toto tissue homeostasis or the response to acute injury (Fig. 1).

Within a facultative regenerative tissue, several different cell lineages may exist as fully differentiated cells with a defined physiological function separate from cellular renewal during homeostasis but, upon injury or in diseased states, exhibit stem/progenitor activity. Such cells, which we refer to as facultative stem/progenitor cells, can contribute to restoration of functional tissues through their ability to re-enter the cell cycle and differentiate into a limited number of daughter cells. Facultative stem/progenitor cells retain a distinct cellular state or lineage within a larger cell population (Fig. 2). In many respects, the facultative stem/progenitor cell is a functionally mature cell waiting for tissue injury or disease initiation to activate its regenerative response. Such a cell is generally part of a larger functionally important cell population

(C) 2018 Leach and Morrisey This article is distributed exclusively by Cold Spring Harbor Laboratory Press for the first six months after the full-issue publication date (see http://genesdev.cshlp.org/site/misc/ terms.xhtml). After six months, it is available under a Creative Commons License (Attribution-NonCommercial 4.0 International), as described at http://creativecommons.org/licenses/by-nc/4.0/. 


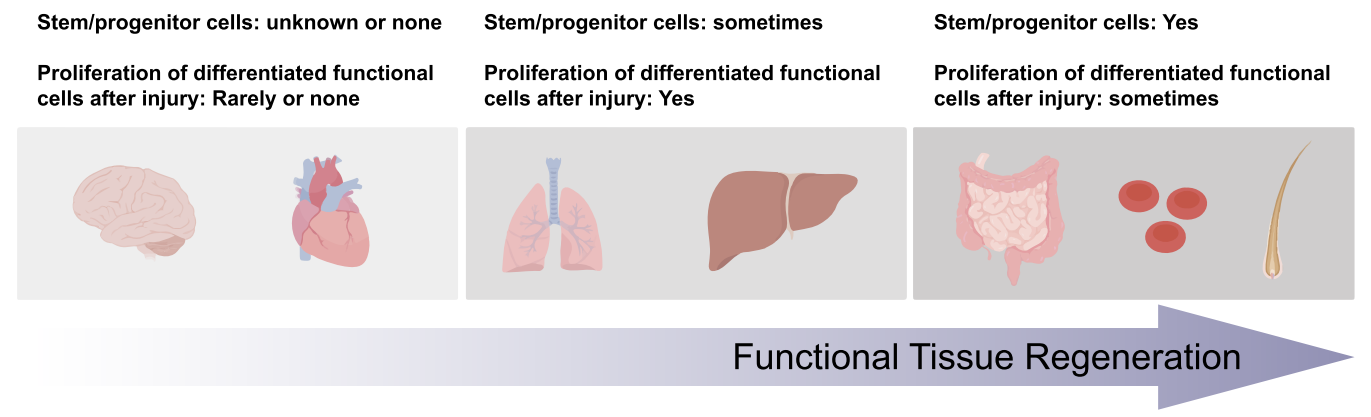

Figure 1. Functional tissue regeneration proceeds as a spectrum among various tissue types. (Right panel) Tissues with dedicated stem cell populations display the most robust regenerative response, including the intestinal crypt, hematopoiesis, and the hair follicle. (Middle panel) Tissues with facultative stem cells maintain a limited regenerative capacity that generally is displayed by subsets of cells proliferating after injury. These tissues include the liver and lungs. (Left panel) Finally, other tissues have no discernable stem cell population, do not exhibit efficient tissue regeneration, and often form scar tissue in response to injury. These tissues include the brain and heart.

that has an important role outside of its stem/progenitor activity (Fig. 2). This is in contrast to the somatic or tissue-specific stem cell, which maintains a quiescent state characterized by genomic, metabolic, and proteomic dormancy and functions primarily as a stem cell. Furthermore, the facultative cell is distinct from the dedifferentiated/transdifferentiated cell. The facultative cell is also transcriptionally similar to the larger cell population of which it is a part but could maintain a distinct genetic or epigenetic state (Fig. 2; Cheung and Rando 2013; Rodgers et al. 2014; Signer et al. 2014).

Conceptually, facultative regeneration has some distinct advantages compared with a more classic stem cell/ differentiated cell hierarchy. In facultative regeneration, tissue repair is accomplished by allowing fully differentiated cells or a sublineage embedded within them to re-enter the cell cycle, proliferate, and differentiate into a restricted repertoire of other cells. In the liver, hepatocytes (or a subset of them) can rapidly proliferate and regenerate the organ after acute injury or partial hepatectomy (Wang et al. 2015; Lin et al. 2018). In the distal lung, a subset of alveolar type 2 (AT2) cells called alveolar epithelial progenitors (AEPs) rapidly re-enter the cell cycle, proliferate to replace lost AT2s, and, over time, differentiate into AT1 cells
(Nabhan et al. 2018; Zacharias et al. 2018). In both situations, the regenerative capacity is derived from what appear to be fully differentiated cell populations. The advantage of this mode of regeneration is that a tissue does not have to dedicate and protect a unique cell lineage for the sole purpose of retaining stem cell activity. This would also help disperse the risk of organ failure during homeostasis or regeneration. Facultative regenerative lineages often comprise a larger percentage of the overall cell number than dedicated stem cell lineages and are often found randomly distributed throughout the tissue, offering the ability to respond robustly and in a nonbiased spatial manner for rapid recovery of function. In larger tissues, a sizable number of facultative stem/progenitor cells would allow for a more rapid response to acute injury to maintain tissue integrity.

A deep understanding of dedicated stem cell lineages has informed our understanding of the generation and regeneration of multiple tissues. However, our understanding of how facultative regenerative tissues such as the lungs, liver, pancreas, and kidneys respond to injury and regenerate lost structures and cells has lagged. Consideration of the advantages and disadvantages of facultative regeneration may allow for a better understanding of
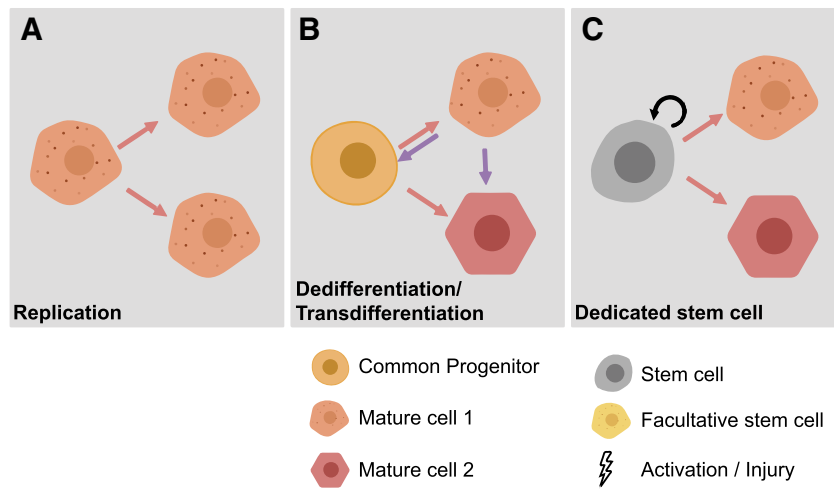

Dedicat

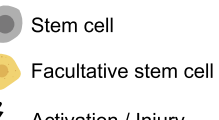

D
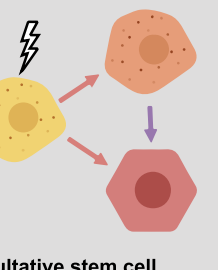

Facultative stem cell

Figure 2. Comparison of cell behaviors in tissues containing dedicated or facultative stem/progenitor cells. (A) Some tissues, such as the liver, exhibit extensive injuryinduced cell replication without the necessity of a well-defined stem/progenitor cell population. $(B)$ In some tissues, such as the large pseudostratified epithelium of the trachea, a differentiated secretory cell can dedifferentiate back into a stem/progenitor basal cell state and then redifferentiate as needed. $(C)$ Tissues such as the intestine and skin contain well-characterized and dedicated stem cells that self-renew and are multipotent. (D) Tissues such as the lung alveolus and certain parts of the proximal airways contain functional cell lineages that act as facultative stem/progenitor cells during homeostasis and are also activated to function as stem/progenitor cells upon injury. 
how and why different tissues repair and regenerate in different manners. In this review, we discuss how facultative regenerative capacity is spatially restricted in some tissues and also explore whether facultative stem/progenitor cells require a distinct supportive niche in a manner similar to dedicated tissue stem cells. The critical signaling pathways and transcriptional responses involved in facultative stem/progenitor cell niche development, maintenance, and response to injury or disease are also discussed.

\section{The pulmonary system as a model to study dedicated vs. facultative stem cell niches and tissue regeneration}

The pulmonary system is an ideal tissue to explore the differences and similarities between facultative and dedicated stem cells and their role in tissue regeneration. In mice, the respiratory system is specified at approximately embryonic day 9.0 (E9.0) within the ventral anterior foregut. At this time, the definitive pulmonary endoderm is demarcated by expression of the transcription factor Nkx2-1 on the ventral side of the anterior foregut endoderm (Minoo et al. 1999). Rapidly after the appearance of $\mathrm{Nkx} 2-1^{+}$endoderm progenitors, the anterior foregut evaginates ventrally through lateral invasion of the surrounding mesenchyme to form the primitive trachea. Subsequent to this process, the growing endoderm begins the process of branching morphogenesis to generate the extensive arborized airway tree. During branching morphogenesis, which ends at approximately E16-E17 in mice, both the endoderm and surrounding mesoderm are patterned in a distinctive manner to generate the various epithelial and mesenchymal lineages in the adult lung (for review, see Morrisey and Hogan 2010; Herriges and Morrisey 2014; Stabler and Morrisey 2017). This patterning process has been studied extensively over the last few decades, and multiple signaling pathways have been identified that promote either a proximal or distal epithelial or mesenchymal cell fate, including Wnt, Notch, Bmp, and Hippo signaling (for review, see Morrisey and Hogan 2010; Herriges and Morrisey 2014).

Even within a single organ such as the lungs, different regions exhibit different strategies for tissue regeneration. Tracheal and large proximal airway cellular renewal is driven primarily by the airway basal cell, which can selfrenew and regenerate both luminal secretory and multiciliated epithelial cells during homeostatic turnover as well as after acute injury (Fig. 3). In addition to the basal cell, certain populations of secretory cells can act as facultative progenitors capable of both self-renewal and differentiation into multiciliated cells (Fig. 3; Reynolds et al. 2000; Giangreco et al. 2002).

In the distal gas exchange compartment in the lung, called the alveolus, there are two types of epithelial cells: the AT1 cell and the AT2 cell. The ability of AT2 cells to self-renew and differentiate into AT1 cells was first described in the early 1970s (Evans et al. 1973, 1975) and was further characterized more recently through lineage tracing studies (Barkauskas et al. 2013). Emerging data have revealed a subset of the AT2 cell population, distinguished by Axin2 expression and termed AEPs, that both promotes homeostatic repopulation of AT1 and AT2 cells and provides for alveolar epithelial regenerative response after acute injury (Fig. 4; Nabhan et al. 2018; Zacharias et al. 2018). As AEPs are embedded within the overall AT2 cell population and appear to have most if not all of the functional capacities as other AT2 cells, they can be defined as a facultative stem/progenitor cell within the lung alveolus.

\section{Stem cells of the lung airway}

The proximal-distal patterning of the airways in the respiratory system helps to define the differentiation and spatial patterning of the basal stem cell lineage within the large proximal airways of the lungs and trachea (Rock et al. 2009a). As their name implies, basal cells are found on the basal surface of the pseudostratified epithelium, where they make intimate contact with both the basal surface and the more luminal secretory and multiciliated epithelium of the large airways (Fig. 5). Recent evidence has revealed that basal cells are defined early in lung development as multipotent progenitors but become restricted to their basal cell fate by E13.5 in mice (Yang et al. 2018). Basal cells in the lungs and elsewhere express a canonical set of markers, including the transcriptional regulator Trp63 and certain keratins, including Keratin 5 (Krt5). Interestingly, basal cells are distributed differently throughout the trachea and airways of the mouse and human respiratory system. In mice, $\operatorname{Trp} 63^{+} / \mathrm{Krt} 5^{+}$basal cells are found only in the trachea and main stem bronchi, with a small population of $\operatorname{Trp} 63^{+} / \mathrm{Krt}^{-}$immature basal cells found more distally (Yang et al. 2018). In contrast, the human respiratory system contains basal cells underlying the airway epithelium distally all the way down to the terminal bronchioles (Nakajima et al. 1998; Rock et al. 2010). This anatomical difference may reflect the need of a more committed stem cell population in a larger organ

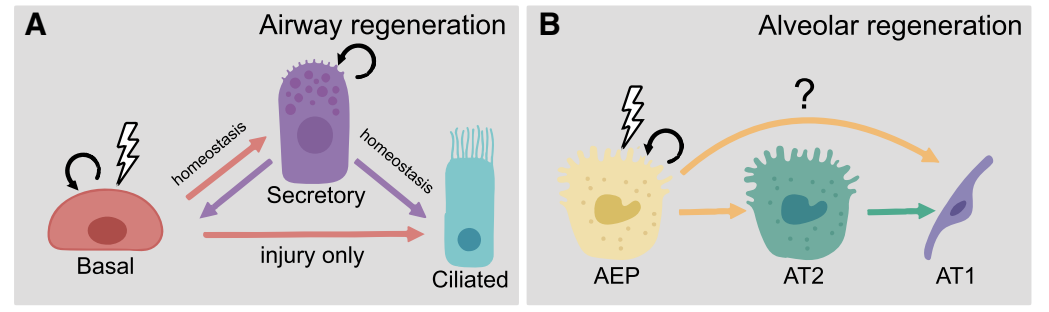

Figure 3. Response of airway and alveolar niches to acute injury and regeneration. $(A)$ In the lung airways, basal cells self-renew and differentiate into secretory and multiciliated cells after injury. Secretory cells can also self-renew and differentiate into multiciliated cells in mice, but it is unclear whether this occurs in human airways. $(B)$ In the lung alveolus, the Axin2 $2^{+}$AEP self-renews and differentiates into mature AT2 and AT1 cells after injury. 


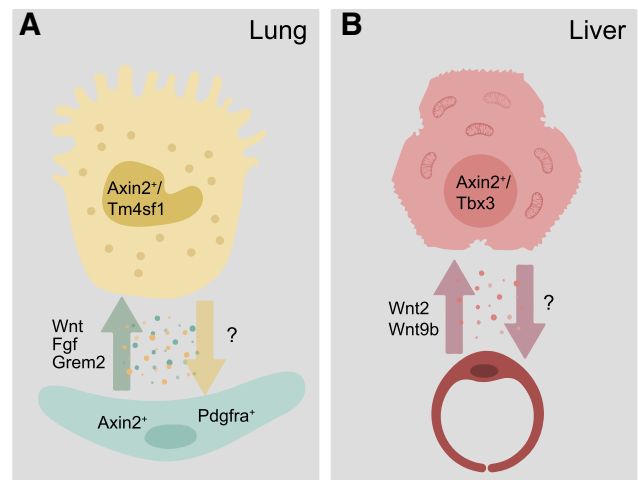

Figure 4. Comparison between the niche signals in lung alveolar and liver regeneration. (A) The mesenchymal alveolar niche cells (MANCs)/AT2-associated stromal cells (TASCs) provide key proregenerative signals to the Axin $2^{+} / \mathrm{Tm} 4 \mathrm{sf} 1^{+} \mathrm{AEPs}$ that activate cell proliferation and differentiation, including Wnt, Fgf, and Bmp signals. The signals emanating from AEPs that are received by MANCs/TASCs are still poorly understood. $(B)$ In the liver, vascular endothelium produces Wnt2 and Wnt9b, which activate the Axin $2^{+} / \mathrm{Tbx} 3^{+}$hepatocyte population to promote liver regeneration.

with greater conducting airway surface. Together, these studies show that the basal cell is an example of a dedicated or committed stem cell population of the lung airway. Certain physiological functions have been attributed to the basal cell, including maintaining attachment of other luminal epithelium to the basement membrane (Evans et al. 2001).

During normal human lung homeostasis, basal cell proliferation is minimal with limited turnover of basal, secretory, and multiciliated epithelial lineages. However, acute damage by either chemical insults or viral infection rapidly activates basal cell proliferation and subsequent differentiation (Hong et al. 2004; Rock et al. 2009b). Techniques have been developed to isolate and culture basal cells from the mouse and human trachea and lung airways, including air-liquid interface cultures and organoid culturing systems (Rock et al. 2009a; Tata et al. 2013; Hynds et al. 2016). Using organoid assays to test basal stem cell competence and self-renewal, several laboratories have demonstrated that basal cells can clonally generate both secretory and multiciliated epithelial cells without the need for mesenchymal cell support (Rock et al. 2009b, 2011; Mou et al. 2016). The resulting organoids, often referred to as tracheospheres, provide a useful model system in which to study basal cell characteristics.

Using lineage tracing techniques, basal cells in mice have similarly been shown to generate both luminal secretory and multiciliated cells during normal homeostatic turnover as well as after acute injury (Watson et al. 2015). This process is controlled in part by Notch signaling, which promotes a secretory cell phenotype over a multiciliated cell phenotype (Rock et al. 2011; Mori et al. 2015). Interestingly, in basal cell ablation experiments, two divergent secretory cell responses are observed. First, a limited number of secretory cells are capable of dedifferentiation into basal cells after basal cell ablation (Tata et al. 2013). Second, transient amplifying secretory cells terminally differentiate into ciliated cells (Pardo-Saganta et al. 2015). The precise mechanisms that direct secretory cell dedifferentiation after basal cell ablation remain elusive. However, it is clear that basal cells provide a Notch signal forward to their own secretory cell progeny to maintain the differentiated secretory cell state (Pardo-Saganta et al. 2015). This type of forward signal is unusual but could be beneficial in maintaining the pseudostratified architecture of the upper airway, where the basal cell and its progeny maintain a direct connection (Xin et al. 2016). These data also suggest that the basal cell can act as an important component of the airway niche, thus conferring a role beyond acting as a stem cell (Tata and Rajagopal 2016). Furthermore, recent evidence suggests that basal cells form their own niche, where mesenchyme-expressed Fgf10 suppresses Hippo signaling to maintain nuclear Yap activity. In this model, Wnt7b expression by basal cells provides a feedback signal to promote Fgf10 expression (Volckaert et al. 2017). Injury can induce basal cell spreading, destabilizing the upstream Hippo signaling factor Merlin, activating nuclear localization of Yap, and promoting the Wnt7b and Fgf10 expression loop (Volckaert et al. 2017).

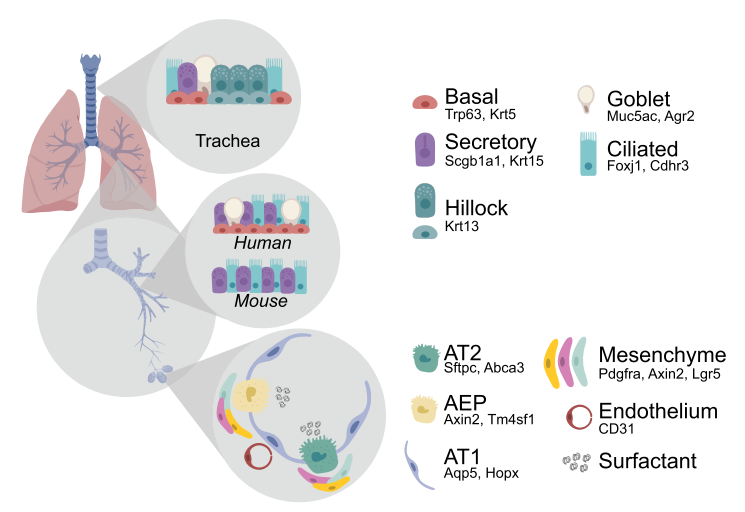

Figure 5. The adult lung contains multiple cell lineages that regenerate the airway and alveolar niches. There are three basic compartments in the lung: the trachea, the proximal airway niche (top two panels), and the distal alveolar niche (bottom panel). Both are comprised of multiple epithelial and mesenchymal lineages, as indicated with useful marker genes noted. In the human respiratory system, proximal airways are underlined by basal cells, while, in mice, basal cells extend only through the main stem bronchi. Moreover, in uninjured mouse lungs, airways generally lack goblet cells. Recent studies have described a subset of basal and secretory cells located in what has been named "hillocks." In the alveolus, AEPs represent a subset of AT2 cells defined by Axin2 and Tm4sf1 expression. Adjacent to both airways and alveoli, there is heterogeneity in the mesenchymal cell lineages, including endothelial cells, some of which support the alveolar epithelium through paracrine signaling and help to define the alveolar niche. While several nonendothelial mesenchymal cell types have been described, including MANCs, TASCs, and $\mathrm{Lgr}^{+}$cells, the similarities or differences between these lineages remain unclear. 
In addition to their role in proximal airway and tracheal regeneration, a subpopulation of basal cells responds after acute lung injury by expanding into the distal lung parenchyma to form large epithelial "pods" (Vaughan et al. 2015; Zuo et al. 2015). While these cells were originally thought to contribute to alveolar regeneration after acute influenza injury (Zuo et al. 2015), recent evidence indicates that they do not regenerate AT1 or AT2 cells but rather re-epithelialize severely damaged regions of the lung to maintain architectural integrity (Vaughan et al. 2015; Kanegai et al. 2016). However, upon manipulation of Wnt signaling or hypoxia, these cells can acquire an AT2-like phenotype (Xi et al. 2017). While these cells appear to radiate out of the airways and express Trp63 and Krt5 once they have formed the large pod structures, the precise cell of origin remains unclear. The most definitive experiments to date have shown that they arise from a Sox $2^{+}$airway epithelial population, and some studies have suggested that they arise from an immature Trp63 ${ }^{+} / \mathrm{Krt5}^{-}$airway population (Ray et al. 2016; Yang et al. 2018). Further research will be needed to better understand the reparative process mediated by these Sox $2^{+} / \operatorname{Trp} 63^{+}$basal-like cells and whether they can be leveraged to promote true alveolar regeneration through reprogramming into the AT1 and/or AT2 cell fates.

A pair of recent studies focused on defining airway cell heterogeneity described a previously unidentified airway cell type, the ionocyte, which expresses high levels of the cystic fibrosis transmembrane conductance regulator (Cftr) gene (Montoro et al. 2018; Plasschaert et al. 2018). In addition to the identification of the ionocyte, one of these studies described the presence of a subset of basal cells found in unique structures termed "hillocks" (Montoro et al. 2018). The hillock basal cell cycles at a higher rate than the surrounding basal cells and specifically contributes to a subset of "hillock" club cells. Additionally, analysis of pseudotemporally ordered transcriptome trajectories indicate homeostatic production of multiciliated cells from basal cells that first transition through a secretory cell state (Montoro et al. 2018). In contrast, injury appears to induce a transcriptional trajectory in which basal cells transition directly to a multiciliated cell fate without passing through a secretory cell fate (Plasschaert et al. 2018). These new studies increase the multilineage potential of certain basal cell subpopulations to include secretory, ionocyte, tuft, and likely other epithelial cell types.

An additional stem cell population in the lung airways is the recently characterized myoepithelial cells (MECs) located in the submucosal glands (SMGs) surrounding the large airways and trachea. SMGs are found only in the most proximal trachea of the mouse respiratory airways, whereas they are located throughout the cartilaginous airways of the human respiratory tract. While MECs were known to exist for some time, whether they exhibited any stem/progenitor cell activity was not clear. Using multiple lineage tracing techniques along with single-cell transcriptome analysis, two recent reports have shown that MECs express Acta2 and an Acta2-creERT2 mouse line can be used to trace their fate after injury. Upon severe but not mild injury nor during homeostatic turnover, these studies indicate that a portion of Acta2 ${ }^{+}$ MECs can proliferate, migrate out of the SMG, acquire a basal cell-like phenotype, and repopulate secretory and multiciliated cells of the trachea in mice (Lynch et al. 2018; Tata et al. 2018). The investigators have called MECs "reserve" stem cells, since they appear to be activated only after severe injury.

The proximal airways of the mouse lung also contain a population of secretory cells that exhibits facultative progenitor activity (Fig. 5). A subset of Scgbla1 ${ }^{+}$secretory cells lacks expression of cytochrome Cyp2f2 and is often referred to as variant secretory cells (VSCs). These cells express Upk3a and are found near neuroendocrine bodies, which may generate a potential niche environment (Guha et al. 2017). VSCs can both self-renew and differentiate into multiciliated epithelium, depending on the injury model used. In the naphthalene depletion model, Cyp2 $22^{+}$secretory cells are lost over the course of 7-10 d, but the VSCs survive (Stripp et al. 1995; Reynolds et al. 2000; Giangreco et al. 2002). While lineage tracing techniques using a Upk3a-creERT2 driver have revealed the multipotency of VSCs, it remains unclear whether this ability to act as facultative progenitors is reserved only for the Cyp2 $\mathrm{f}^{-}$subpopulation or whether, upon injury, some Cyp2 $2^{+}$cells lose expression of this cytochrome and then are allowed to proliferate and differentiate (Guha et al. 2012, 2017). Despite these uncertainties, VSCs appear to act as facultative progenitor cells for airway epithelial regeneration in regions of the mouse lung that lack basal cells. Whether VSCs exist and play a similar or identical role in the human lung is unknown. However, since basal cells are found throughout most of the human airways, including the terminal bronchioles, it is unclear whether the human airway epithelium would require VSCs for airway regeneration.

\section{Stem cells of the lung alveolus}

In contrast to the trachea and large proximal airways, the distal lung alveolus appears to use a different mode of tissue regeneration, likely due to the developmental and architectural distinctions of this niche. As the distal tip endoderm progenitors in the lung develop and mature in late gestation and during alveologenesis, two major epithelial cell lineages are generated: AT1 and AT2 cells (Fig. 5). Functionally, the AT2 cell is the primary source of surfactant production in the alveolus and can be identified by the presence of lamellar bodies, the tightly packed surfactant-storing organelles (Lopez-Rodriguez et al. 2017). As a mixture of lipids and proteins, surfactant works to reduce surface tension at the air-liquid interface to help maintain alveolar integrity during breathing (Veldhuizen and Haagsman 2000). Furthermore, AT2 cells mediate surfactant catabolism and recycling, modulating the overall alveolar environment to maintain proper surface tension and prevent alveolar collapse (Wright and Clements 1987). In contrast to AT2 cells, AT1 cells are morphologically distinct, with a very large extensive flattened shape. They cover $90 \%-95 \%$ of the alveolar surface area, although they comprise $\sim 50 \%$ of the total alveolar 
epithelial cell population, where they form the thin gasdiffusible interface with the vascular endothelial plexus (Haies et al. 1981; Crapo et al. 1982; Stone et al. 1992).

There is still a paucity of information about the specification and divergence of AT1 and AT2 cells during development. Currently, there are two developmental paradigms that attempt to explain the origins of the AT1 and AT2 cell lineages. Previous studies have presented lineage tracing data to support a model of AT1 and AT2 cell lineage specification that occurs gradually during development after proximal-distal patterning of the endoderm has been established (Perl et al. 2002; Rawlins et al. 2009). More recently, a model of AT1 and AT2 cell divergence was proposed that suggests the existence of a bipotent progenitor in late lung development, located in the very distal portion of the branched airway tips, where it is responsible for generating both AT1 and AT2 cells during sacculation and alveologenesis (Desai et al. 2014; Treutlein et al. 2014). Several questions remain on the nature of this bipotent progenitor, including exactly when it appears, whether it diminishes in number during development, and whether it exists in the adult lung. More data are also needed on the developmental contribution of the bipotent progenitor to the mature alveolus. Stagedependent inducible and clonal lineage tracing throughout development is needed to assess whether bipotent cells expand preferentially or harbor a specific differentiation capacity not present in the committed AT1 or AT2 cell lineages. While identifying stem/progenitor cell types through the expression of single transcription factors, signaling pathway proteins, or a single physiologically consequential gene is a standard approach in most studies (Kretzschmar and Watt 2012), characterizing cell lineages that are difficult to mark with a single gene, such as a bipotent progenitor, could be addressed using intersectional genetic models to lineage-trace cells expressing markers of both the AT1 and AT2 lineages (Awatramani et al. 2003; Devine et al. 2014; Plummer et al. 2015). Such intersectional genetic approaches would help delineate the origin and divergence of the AT1 and AT2 cell lineages in the lung epithelium as well as determine the contribution of the bipotent cells in this process.

During alveologenesis, a unique subset of AT2 cells that express the Wnt target gene Axin2 arises (Fig. 5). These AT2 ${ }^{\text {Axin2 }}$ cells proliferate to a greater extent than other AT2s and are capable of generating AT1 cells during alveologenesis (Frank et al. 2016). Activation of Wnt signaling promotes AT2 ${ }^{\text {Axin2 }}$ cell self-renewal, while inhibition of Wnt signaling promotes their differentiation into AT1 cells (Fig. 5). Importantly, the AT2 Axin2 cell population is rather fluid during the alveologenesis period, with some non-Axin2-expressing AT2 cells acquiring an $\mathrm{AT} 2^{\text {Axin2 }}$ cell phenotype. In the adult lung, AT2 ${ }^{\text {Axin2 }}$ cells become a stable sublineage that self-renews and differentiates into AT1 cells and is called the AEP (Nabhan et al. 2018; Zacharias et al. 2018). The two concurrent studies describing this sublineage use different Axin2creERT2 mouse models that resulted in different relative abundances of AEPs. The Desai group (Nabhan et al.
2018) used an Axin2creERT2 allele, whereas the Morrisey group (Zacharias et al. 2018) used an Axin2creERT2: TdTomato allele that can report steady-state levels of Axin 2 expression in addition to the inducible lineage trace using the creERT2 recombinase. The relative abundance estimated by the Morrisey group (Zacharias et al. 2018) ranged between $20 \%$ and $30 \%$, which was primarily based on the steady-state TdTomato expression. This circumvents issues of cre recombinase efficiency by establishing absolute cell numbers directly from the tdTomato expression reporter (Heffner et al. 2012). The Morrisey group (Zacharias et al. 2018) also identified a cell surface marker expressed by mouse AEPs, Tm4sf1, and used this to identify and characterize human AEPs, which similarly represented $25 \%-30 \%$ of the human AT2 cell population. Using the comparison between the lineage-traced AEPs and the expression of the steady-state TdTomato reporter, the Morrisey group (Zacharias et al. 2018) demonstrated that mouse AEPs are a relatively stable population of cells for up to 9 mo. While data from the Desai group (Nabhan et al. 2018) suggested that Axin2 expression was induced after acute viral lung injury, the Morrisey group (Zacharias et al. 2018) did not observe a post-injury induction of Axin2 expression. Data from both groups indicate that the Axin2-expressing AT2 cell population is uniquely capable of responding to injury by re-entering the cell cycle and contributing to tissue regeneration (Nabhan et al. 2018; Zacharias et al. 2018). Furthermore, part of the distinctive nature of AEPs comes from their unique chromatin state compared with other AT2 cells, which suggests a "primed" state for the purpose of regenerating lost alveolar epithelium through re-entry into the cell cycle (Zacharias et al. 2018). Despite the chromatin state differences, AEPs exhibit many if not most of the attributes of other AT2 cells, including expression of surfactant protein genes. Whether they are functionally equivalent to nonAxin2-expressing AT2s in their abilities to generate and recycle surfactant remains to be determined. In future studies, it will be important to determine whether there are other subsets of AT2 cells capable of responding to other types of injury that induce different cellular responses.

While the recent studies describing the importance of AEPs in lung alveolar regeneration indicate that Fgf and Wnt signaling plays important roles in their self-renewing capacity, the molecular mechanisms controlling differentiation into AT1 cells remain unclear (Nabhan et al. 2018; Zacharias et al. 2018). Clues from AT1 and AT2 cell development suggest that a unique interplay between mechanical forces and cell-cell interactions may help specify developmental alveolar progenitors into either AT1 or AT2 cells (Li et al. 2018). In this study, FGF10/ FGFR2 signaling between a subset of epithelial progenitors and the underlying mesenchyme creates an actinbased cell protrusion and reduces the apical surface area, characterized by an enrichment in myosin. This prevents mechanical forces from flattening the cell, and thus the cells with protrusions and an apical myosin ring are specified as AT2 cells. Ostensibly, the flattened cells that do not react to these signals become AT1 cells. In 
this model, a niche is created that maintains the AT2 cell as an alveolar progenitor, while stretch-mediated mechanical forces specify the AT1 cell fate. Interestingly, a recent study suggests that the mechanosensing pathway Hippo is regulated in part by claudin-18 to govern lung growth. In this study, claudin-18 knockout mice have increased lung size coincident with an increase in nuclear YAP activity and increased cellular proliferation (Zhou et al. 2018). Whether Hippo signaling plays an important role in AT1 and AT2 cell proliferation and differentiation either in development or after lung injury remains to be determined.

Given the space constraints of the lung alveoli, cell-cell communication directing regenerative ability is integral to proper stimulation of growth. Endothelial stimulation of AT2 cell growth appears to underlie compensatory regrowth in a unilateral pneumonectomy model of lung injury (Ding et al. 2011). In this model, epithelialderived MMP14 unmasks EGF-like ectodomains on AT2 cells that in turn activate EGF receptors and stimulate AT2 cell expansion. Moreover, the epithelium appears to form a niche permissive to epithelial reconstitution and engraftment (Cao et al. 2017). Other studies have provided evidence that interactions between AT2 cells and the underlying mesenchyme are required to maintain the AT2 facultative state and promote proliferation and differentiation in this cell population after injury (Barkauskas et al. 2013; Liang et al. 2016; Lee et al. 2017; Zepp et al. 2017; Chung et al. 2018). Some of the signals involved include Wnt, Fgf, Bmp, and IL6.

Concurrent reports of mesenchymal heterogeneity implicate interactions between the epithelium and subsets of underlying mesenchymal cells (Lee et al. 2017; Zepp et al. 2017; Chung et al. 2018). Furthermore, the mesenchymal alveolar niche cell (MANC) identified by expression of Axin2 and Pdgfra is capable of promoting maximal alveolar growth and regeneration through expression of Fgf7, IL6, and Bmp inhibitors such as Grem2 (Zepp et al. 2017). Activation of BMP in Pdgfra ${ }^{+}$mesenchymal cells, referred to as an AT2-associated stromal cell (TASC), inhibits AT2 cell self-renewal after pneumonectomy (Chung et al. 2018). In addition to MANCs and TASCs, distinct Lgr $5^{+}$lung mesenchymal cells can also promote differentiation of epithelial progenitors through Wnt activation (Lee et al. 2017). These studies also indicate that expression of BMP antagonists Grem2, Fstl1, or Fst in mesenchymal cells such as MANC/TASCs and possibly Lgr $5^{+}$cells could be promoting and maintaining the AT2 cell facultative state (Zepp et al. 2017; Chung et al. 2018). Further experiments are needed to determine the overlap between these subsets of mesenchymal cells in the lung and whether there is additional functional heterogeneity. Finally, it will be important to determine how these different sublineages of mesenchymal cells interact with AT2 cells to create a facultative stem cell niche.

\section{Facultative stem/progenitor cells in other tissues}

The above anatomical and cellular descriptions of the various regions of the mammalian lung raise an interest- ing question: Why do some compartments have a dedicated stem cell lineage, while others contain more facultative progenitors? Multiple reasons for this distinction could include the rate of cellular turnover, space constraints within the tissue, or even the speed of cellular response necessary to replace lost or damaged cells and maintain tissue architecture. Importantly, the lung requires replacement of a large and very thin surface area after injury, whereas tissues with highly dedicated stem cells require mostly volumetric or cell number replacement.

When conceptualizing the spectrum from dedicated to facultative stem/progenitor cells, there are likely to be few absolutes in either extreme category. Both basal cells and AEP cells could be considered facultative or dedicated, depending on the definition of these two terms. A major distinction between basal and AEP cells is that basal cells contribute to multiple cell types in the lung airway, whereas the AEP cells appear to self-renew and contribute to only one other cell type: the AT1 cells. Both basal cells and AEPs appear to be long-lived and phenotypically stable cells, which could suggest a more dedicated role as a stem/progenitor cell. However, the difference between dedicated and facultative stem/progenitor cells may be better defined by whether they appear within a larger cell population and exhibit distinctive and robust functional roles important for tissue homeostasis, in addition to their ability to exhibit multilineage differentiation capabilities. Thus, since AEPs look very much like other AT2 cells, they are better defined as a facultative progenitor, while basal cells have a unique phenotype in the large airways of the lung and can robustly self-renew and differentiate into multiple other lineages, making them appear more dedicated in their stem cell role. Despite such definitions, there are likely many cell types from other tissues that can be found along the entire spectrum from dedicated to facultative.

In the liver, there have been several studies revealing a specialized subtype of hepatocyte that can be distinguished by expression of markers such as Axin2 or telomerase that are critical for liver regeneration (Miyajima et al. 2014). Axin2 expression marks a subset of hepatocytes adjacent to the liver central vein that are capable of contributing to hepatocyte renewal (Fig. 4; Wang et al. 2015). These Axin $2^{+}$hepatocytes are distinguished from mature hepatocytes in other ways, including their expression of the liver progenitor marker Tbx3. Moreover, these cells are diploid, whereas mature hepatocytes are polyploid. In contrast to the lung AEPs, which rely on an interaction with closely associated mesenchymal cells, the liver Axin $2^{+}$hepatocytes associate with nearby endothelium. The Wnt signal maintaining the Axin2 ${ }^{+}$ state appears to be derived from adjacent endothelial cells expressing $W n t 2$ and $W n t 9 b$, thereby establishing a hepatocyte-endothelial anatomical niche (Fig. 4). Also, these cells appear to be stable and capable of self-renewal, with some studies suggesting that this does not represent a dedifferentiation/redifferentiation model of hepatocyte renewal (Wang et al. 2015). Periportal hepatocytes expressing low levels of Sox9 and hepatocytes distributed 
throughout the liver expressing TERT also appear to exhibit regenerative abilities after injury (Font-Burgada et al. 2015; Lin et al. 2018). The requirement of TERT to maintain the renewal capability of these cells would suggest a progressive loss of renewal ability with aging, dependent on telomere integrity. It is unclear whether the Sox $9^{+}$periportal hepatocytes or the TERT ${ }^{+}$hepatocytes are maintained in a niche that supports self-renewal. Other studies have suggested that most if not all hepatocytes may exhibit the ability to proliferate and regenerate the liver after injury (Malato et al. 2011; Yanger et al. 2014). This would represent the most democratic way to disperse facultative regeneration, giving all cells the ability, under specific and controlled circumstances, to proliferate and regenerate most cells within a tissue.

In addition to hepatocytes, cholangiocytes or biliary bile duct cells have also been shown to contribute to liver regeneration after injury when self-replication-derived hepatocyte renewal is impaired (He et al. 2014; Raven et al. 2017). Whether cholangiocyte-dependent hepatocyte regeneration is as efficient as that observed through hepatocyte self-renewal described above remains unclear. Moreover, the signaling and transcriptional responses that distinguish these two modes of liver regeneration are poorly understood.

In tissues where mature cell types can contribute to regenerative processes, not every differentiated cell of a particular lineage is intrinsically capable of contributing to the regenerative process. Instead, definable niche characteristics often exist and can be used to distinguish facultative cells from other fully differentiated cell types. Furthermore, it has become increasingly clear that cellular niches are made of more than just cells. The extracellular matrix and other noncellular mechanisms are known to help coordinate cellular niche behaviors (Wang and Wagers 2011; Gattazzo et al. 2014; Xin et al. 2016). In skeletal muscle, emerging evidence suggests that a robust regenerative response requires a scaffold from which to build to restore functional tissue. Indeed, myogenic progenitors require guidance from "ghost fibers" in order to restore properly oriented muscle fibers (Webster et al. 2016). In this example, remnants of the extracellular matrix of the basal lamina help to orient regeneration of muscle fibers in the correct orientation, presumably through orchestration of signaling molecules and growth factors maintained in the matrix milieu. Such cellular remnants may provide an important scaffold for alveolar regeneration in the lung.

In the skin, complete neogenesis of hair follicles has been demonstrated, suggesting that, at least in certain contexts, residual tissue may not be required for regeneration (Ito et al. 2007; Gay et al. 2013; Nelson et al. 2015). De novo folliculogenesis requires Wnt ligand expression after re-epithelialization of a skin wound in mice (Ito et al. 2007). Subsequent studies indicated that epidermal $\gamma \delta$ T cells produce Fgf9, which triggered Wnt expression by fibroblasts, and, through a feedback mechanism, the activated fibroblasts amplify the Fgf9 signal, which is sufficient to activate Wnt ligand expression, specifying epidermal activation and hair follicle formation (Gay et al.
2013). Hair follicle regeneration is not an essential aspect of skin wound healing and is absent in humans. However, these studies highlight the important contribution of the immune system to tissue regeneration beyond basic wound healing. More recently, single-cell transcriptional profiling of epidermal and hair follicle heterogeneity indicates a lock of a "stemness" gene signature in basal cells (Joost et al. 2016). The investigators speculate that basal stem cell function is dependent on spatial positioning within a tissue and could be a product of maintaining attachment to the basement membrane. The intricately described spatial layout of the hair follicle allowed the investigators to reconstruct a proximal-distal gene expression axis to describe cellular differentiation. As with the recent reports of single-cell transcriptome profiling in the lung airway, basal cell differentiation trajectories can be constructed from single-cell transcriptome profiles (Joost et al. 2016; Montoro et al. 2018; Plasschaert et al. 2018).

Regenerative systems requiring a scaffold or being capable of de novo formation may have developmental origins. Conceptionally, rebuilding the architecture of the alveoli and having that integrate into the airway would be challenging. Could epithelial-mesenchymal interactions that integrate mechanical feedback, such as those described in the developing alveolus, lead to self-organization of de novo alveoli during regeneration, or is a matrix scaffold required for proper patterning of alveolar structure? Does the immune system provide instructions for de novo alveoli regeneration? As the field progresses, it will be important to discern how the various cell types of the lung interact to maintain the alveolar niche and what contributions each cell type provides to the regeneration of alveoli.

\section{Conclusions}

A robust understanding of the tissue-regenerative processes at play in the adult mammalian lung will allow for targeted therapies that improve or induce a reparative response when it is otherwise ineffective. This will require a more detailed understanding of the signaling and transcriptional pathways that activate reparative programs after injury or in chronic diseases. Studies in tissues outside of the lung will continue to inform the pulmonary regeneration field. In the case of a facultative stem celldriven process, careful consideration must be made to acknowledge the functional roles of these cells in the maintenance of overall tissue homeostasis. In the lung alveoli, any method that aims to improve the regenerative response will need to consider the implications on surfactant production and immune regulation. Furthermore, stimulating the creation of more cells might not be enough to initiate self-organization of functional alveoli. A more detailed understanding of how the lung alveolus and airways are specified and maintained throughout development and in the adult will provide important insights to better understand how to regenerate destroyed or defective lung tissue. Moreover, while much headway has been made in understanding the cellular responses 
and signaling activators important for lung regeneration, there is still a paucity of data to describe the steady and activated epigenetic states of these cells. To this end, recent advances in single-cell transcriptomics, chromatin profiling, lineage tracing, and cell-cell interaction studies will undoubtedly help to propel the field forward.

\section{References}

Awatramani R, Soriano P, Rodriguez C, Mai JJ, Dymecki SM. 2003. Cryptic boundaries in roof plate and choroid plexus identified by intersectional gene activation. Nat Genet 35: 70-75. doi:10.1038/ng1228

Barkauskas CE, Cronce MJ, Rackley CR, Bowie EJ, Keene DR, Stripp BR, Randell SH, Noble PW, Hogan BL. 2013. Type 2 alveolar cells are stem cells in adult lung. J Clin Invest 123: 3025-3036. doi:10.1172/JCI68782

Cao Z, Ye T, Sun Y, Ji G, Shido K, Chen Y, Luo L, Na F, Li X, Huang $Z$, et al. 2017. Targeting the vascular and perivascular niches as a regenerative therapy for lung and liver fibrosis. Sci Trans1 Med 9: eaai8710. doi:10.1126/scitranslmed.aai8710

Chen CH, Poss KD. 2017. Regeneration genetics. Annu Rev Genet 51: 63-82. doi:10.1146/annurev-genet-120116-024554

Cheung TH, Rando TA. 2013. Molecular regulation of stem cell quiescence. Nat Rev Mol Cell Biol 14: 329-340. doi:10.1038/ nrm3591

Chung MI, Bujnis M, Barkauskas CE, Kobayashi Y, Hogan BLM. 2018. Niche-mediated BMP/SMAD signaling regulates lung alveolar stem cell proliferation and differentiation. Development 145: dev163014. doi:10.1242/dev.163014

Cossu G, Birchall M, Brown T, De Coppi P, Culme-Seymour E, Gibbon S, Hitchcock J, Mason C, Montgomery J, Morris S, et al. 2018. Lancet commission: stem cells and regenerative medicine. Lancet 391: 883-910. doi:10.1016/S0140-6736(17) 31366-1

Crane GM, Jeffery E, Morrison SJ. 2017. Adult haematopoietic stem cell niches. Nat Rev Immunol 17: 573-590. doi: 10.1038/nri.2017.53

Crapo JD, Barry BE, Gehr P, Bachofen M, Weibel ER. 1982. Cell number and cell characteristics of the normal human lung. Am Rev Respir Dis 126: 332-337.

Desai TJ, Brownfield DG, Krasnow MA. 2014. Alveolar progenitor and stem cells in lung development, renewal and cancer. Nature 507: 190-194. doi:10.1038/nature12930

Devine WP, Wythe JD, George M, Koshiba-Takeuchi K, Bruneau BG. 2014. Early patterning and specification of cardiac progenitors in gastrulating mesoderm. Elife doi:10.7554/eLife.03848

Ding B-S, Nolan DJ, Guo P, Babazadeh AO, Cao Z, Rosenwaks Z, Crystal RG, Simons M, Sato TN, Worgall S, et al. 2011. Endothelial-derived angiocrine signals induce and sustain regenerative lung alveolarization. Cell 147: 539-553. doi:10.1016/j. cell.2011.10.003

Evans MJ, Cabral LJ, Stephens RJ, Freeman G. 1973. Renewal of alveolar epithelium in the rat following exposure to NO2. Am J Pathol 70: 175-198.

Evans MJ, Cabral LJ, Stephens RJ, Freeman G. 1975. Transformation of alveolar type 2 cells to type 1 cells following exposure to NO2. Exp Mol Pathol 22: 142-150. doi:10.1016/0014-4800 (75) $90059-3$

Evans MJ, Van Winkle LS, Fanucchi MV, Plopper CG. 2001. Cellular and molecular characteristics of basal cells in airway epithelium. Exp Lung Res 27: 401-415. doi:10.1080/ 019021401300317125
Font-Burgada J, Shalapour S, Ramaswamy S, Hsueh B, Rossell D, Umemura A, Taniguchi K, Nakagawa H, Valasek MA, Ye L, et al. 2015. Hybrid periportal hepatocytes regenerate the injured liver without giving rise to cancer. Cell 162: 766-779. doi:10.1016/j.cell.2015.07.026

Frank DB, Peng T, Zepp JA, Snitow M, Vincent TL, Penkala IJ, Cui Z, Herriges MJ, Morley MP, Zhou S, et al. 2016. Emergence of a wave of Wnt signaling that regulates lung alveologenesis by controlling epithelial self-renewal and differentiation. Cell Rep 17: 2312-2325. doi:10.1016/j.celrep.2016.11.001

Gattazzo F, Urciuolo A, Bonaldo P. 2014. Extracellular matrix: a dynamic microenvironment for stem cell niche. Biochim Biophys Acta 1840: 2506-2519. doi:10.1016/j.bbagen.2014. 01.010

Gay D, Kwon O, Zhang Z, Spata M, Plikus MV, Holler PD, Ito M, Yang Z, Treffeisen E, Kim CD, et al. 2013. Fgf9 from dermal $\gamma \delta$ $\mathrm{T}$ cells induces hair follicle neogenesis after wounding. Nat Med 19: 916-923. doi: $10.1038 / \mathrm{nm} .3181$

Giangreco A, Reynolds SD, Stripp BR. 2002. Terminal bronchioles harbor a unique airway stem cell population that localizes to the bronchoalveolar duct junction. Am I Pathol 161: 173-182. doi:10.1016/S0002-9440(10)64169-7

Guha A, Vasconcelos M, Cai Y, Yoneda M, Hinds A, Qian J, Li G, Dickel L, Johnson JE, Kimura S, et al. 2012. Neuroepithelial body microenvironment is a niche for a distinct subset of Clara-like precursors in the developing airways. Proc Nat1 Acad Sci 109: 12592-12597. doi:10.1073/pnas.1204710109

Guha A, Deshpande A, Jain A, Sebastiani P, Cardoso WV. 2017. Uroplakin $3 \mathrm{a}^{+}$cells are a distinctive population of epithelial progenitors that contribute to airway maintenance and postinjury repair. Cell Rep 19: 246-254. doi:10.1016/j.celrep. 2017.03.051

Haies DM, Gil J, Weibel ER. 1981. Morphometric study of rat lung cells: I. Numerical and dimensional characteristics of parenchymal cell population. Am Rev Respir Dis 123: 533-541.

He J, Lu H, Zou Q, Luo L. 2014. Regeneration of liver after extreme hepatocyte loss occurs mainly via biliary transdifferentiation in zebrafish. Gastroenterology 146: 789-800 e788. doi:10.1053/j.gastro.2013.11.045

Heffner CS, Herbert Pratt C, Babiuk RP, Sharma Y, Rockwood SF, Donahue LR, Eppig JT, Murray SA. 2012. Supporting conditional mouse mutagenesis with a comprehensive cre characterization resource. Nat Commun 3: 1218. doi:10.1038/ ncomms 2186

Herriges M, Morrisey EE. 2014. Lung development: orchestrating the generation and regeneration of a complex organ. Development 141: 502-513. doi:10.1242/dev.098186

Hong KU, Reynolds SD, Watkins S, Fuchs E, Stripp BR. 2004. In vivo differentiation potential of tracheal basal cells: evidence for multipotent and unipotent subpopulations. Am J Physiol Lung Cell Mol Physiol 286: L643-L649. doi:10.1152/ ajplung.00155.2003

Hynds RE, Butler CR, Janes SM, Giangreco A. 2016. Expansion of human airway basal stem cells and their differentiation as 3D tracheospheres. Methods Mol Biol doi:10.1007/7651_2016_5

Ito M, Yang Z, Andl T, Cui C, Kim N, Millar SE, Cotsarelis G. 2007. Wnt-dependent de novo hair follicle regeneration in adult mouse skin after wounding. Nature 447: 316-320. doi:10.1038/nature05766

Joost S, Zeisel A, Jacob T, Sun X, La Manno G, Lönnerberg P, Linnarsson S, Kasper M. 2016. Single-cell transcriptomics reveals that differentiation and spatial signatures shape epidermal and hair follicle heterogeneity. Cell Syst 3: 221-237.e9. doi: 10.1016/j.cels.2016.08.010 
Kanegai CM, Xi Y, Donne ML, Gotts JE, Driver IH, Amidzic G, Lechner AJ, Jones KD, Vaughan AE, Chapman HA, et al. 2016. Persistent pathology in influenza-infected mouse lungs. Am J Respir Cell Mol Biol 55: 613-615. doi:10.1165/ rcmb.2015-0387LE

Kretzschmar K, Watt FM. 2012. Lineage tracing. Cell 148: 33-45. doi:10.1016/j.cell.2012.01.002

Lee J-H, Tammela T, Hofree M, Choi J, Marjanovic N, Han S, Canner D, Wu K, Paschini M, Bhang D, et al. 2017. Anatomically and functionally distinct lung mesenchymal populations marked by Lgr5 and Lgr6. Cell 170: 1149-1163.e12. doi:10.1016/j.cell.2017.07.028

Li J, Wang Z, Chu Q, Jiang K, Li J, Tang N. 2018. The strength of mechanical forces determines the differentiation of alveolar epithelial cells. Dev Cell 44: 297-312 e295. doi:10.1016/j. devcel.2018.01.008

Liang J, Zhang Y, Xie T, Liu N, Chen H, Geng Y, Kurkciyan A, Mena JM, Stripp BR, Jiang D, et al. 2016. Hyaluronan and TLR4 promote surfactant-protein-C-positive alveolar progenitor cell renewal and prevent severe pulmonary fibrosis in mice. Nat Med 22: 1285-1293. doi:10.1038/nm.4192

Lin S, Nascimento EM, Gajera CR, Chen L, Neuhöfer P, Garbuzov A, Wang S, Artandi SE. 2018. Distributed hepatocytes expressing telomerase repopulate the liver in homeostasis and injury. Nature 556: 244-248. doi:10.1038/s41586-018-0004-7

Lopez-Rodriguez E, Gay-Jordi G, Mucci A, Lachmann N, SerranoMollar A. 2017. Lung surfactant metabolism: early in life, early in disease and target in cell therapy. Cell Tissue Res 367: 721-735. doi:10.1007/s00441-016-2520-9

Lynch TJ, Anderson PJ, Rotti PG, Tyler SR, Crooke AK, Choi SH, Montoro DT, Silverman CL, Shahin W, Zhao R, et al. 2018. Submucosal gland myoepithelial cells are reserve stem cells that can regenerate mouse tracheal epithelium. Cell Stem Cell 22: 779. doi:10.1016/j.stem.2018.04.007

Malato Y, Naqvi S, Schürmann N, Ng R, Wang B, Zape J, Kay MA, Grimm D, Willenbring H. 2011. Fate tracing of mature hepatocytes in mouse liver homeostasis and regeneration. J Clin Invest 121: 4850-4860. doi:10.1172/JCI59261

Minoo P, Su G, Drum H, Bringas P, Kimura S. 1999. Defects in tracheoesophageal and lung morphogenesis in Nkx2.1 $1^{-/-}$mouse embryos. Dev Biol 209: 60-71. doi:10.1006/dbio.1999.9234

Miyajima A, Tanaka M, Itoh T. 2014. Stem/progenitor cells in liver development, homeostasis, regeneration, and reprogramming. Cell Stem Cell 14: 561-574. doi:10.1016/j.stem. 2014.04.010

Montoro DT, Haber AL, Biton M, Vinarsky V, Lin B, Birket SE, Yuan F, Chen S, Leung HM, Villoria J, et al. 2018. A revised airway epithelial hierarchy includes CFTR-expressing ionocytes. Nature 560: 319-324. doi:10.1038/s41586-018-0393-7

Mori M, Mahoney JE, Stupnikov MR, Paez-Cortez JR, Szymaniak AD, Varelas X, Herrick DB, Schwob J, Zhang H, Cardoso WV. 2015. Notch3-Jagged signaling controls the pool of undifferentiated airway progenitors. Development 142: 258-267. doi:10.1242/dev.116855

Morrisey EE, Hogan BL. 2010. Preparing for the first breath: genetic and cellular mechanisms in lung development. Dev Cell 18: 8-23. doi:10.1016/j.devcel.2009.12.010

Mou H, Vinarsky V, Tata PR, Brazauskas K, Choi SH, Crooke AK, Zhang B, Solomon GM, Turner B, Bihler H, et al. 2016. Dual SMAD signaling inhibition enables long-term expansion of diverse epithelial basal cells. Cell Stem Cell 19: 217-231. doi:10.1016/j.stem.2016.05.012

Nabhan AN, Brownfield DG, Harbury PB, Krasnow MA, Desai TJ. 2018. Single-cell Wnt signaling niches maintain stemness of alveolar type 2 cells. Science 359: 1118-1123. doi:10.1126/ science.aam 6603

Nakajima $M$, Kawanami O, Jin E, Ghazizadeh $M$, Honda $M$, Asano G, Horiba K, Ferrans VJ. 1998. Immunohistochemical and ultrastructural studies of basal cells, Clara cells and bronchiolar cuboidal cells in normal human airways. Pathol Int 48: 944-953. doi:10.1111/j.1440-1827.1998.tb03865.x

Nelson AM, Reddy SK, Ratliff TS, Hossain MZ, Katseff AS, Zhu AS, Chang E, Resnik SR, Page C, Kim D, et al. 2015. dsRNA released by tissue damage activates TLR3 to drive skin regeneration. Cell Stem Cell 17: 139-151. doi:10.1016/j. stem.2015.07.008

Pardo-Saganta A, Tata PR, Law BM, Saez B, Chow RD, Prabhu M, Gridley T, Rajagopal J. 2015. Parent stem cells can serve as niches for their daughter cells. Nature 523: 597-601. doi:10.1038/nature 14553

Perl AK, Wert SE, Nagy A, Lobe CG, Whitsett JA. 2002. Early restriction of peripheral and proximal cell lineages during formation of the lung. Proc Natl Acad Sci 99: 10482-10487. doi:10.1073/pnas.152238499

Plasschaert LW, Žilionis R, Choo-Wing R, Savova V, Knehr J, Roma G, Klein AM, Jaffe AB. 2018. A single-cell atlas of the airway epithelium reveals the CFTR-rich pulmonary ionocyte. Nature 560: 377-381. doi:10.1038/s41586-018-0394-6

Plummer NW, Evsyukova IY, Robertson SD, de Marchena J, Tucker CJ, Jensen P. 2015. Expanding the power of recombinase-based labeling to uncover cellular diversity. Development 142: 4385-4393. doi:10.1242/dev.129981

Raven A, Lu WY, Man TY, Ferreira-Gonzalez S, O'Duibhir E, Dwyer BJ, Thomson JP, Meehan RR, Bogorad R, Koteliansky V, et al. 2017. Cholangiocytes act as facultative liver stem cells during impaired hepatocyte regeneration. Nature 547: 350-354. doi:10.1038/nature23015

Rawlins EL, Clark CP, Xue Y, Hogan BL. 2009. The Id2 ${ }^{+}$distal tip lung epithelium contains individual multipotent embryonic progenitor cells. Development 136: 3741-3745. doi:10.1242/ dev.037317

Ray S, Chiba N, Yao C, Guan X, McConnell AM, Brockway B, Que L, McQualter JL, Stripp BR. 2016. Rare SOX2 ${ }^{+}$airway progenitor cells generate $\mathrm{KRT} 5^{+}$cells that repopulate damaged alveolar parenchyma following influenza virus infection. Stem Cell Rep 7: 817-825. doi:10.1016/j.stemcr.2016.09.010

Reynolds SD, Giangreco A, Power JH, Stripp BR. 2000. Neuroepithelial bodies of pulmonary airways serve as a reservoir of progenitor cells capable of epithelial regeneration. Am I Pathol 156: 269-278. doi:10.1016/S0002-9440(10)64727-X

Rock JR, Onaitis MW, Rawlins EL, Lu Y, Clark CP, Xue Y, Randell SH, Hogan BL. 2009a. Basal cells as stem cells of the mouse trachea and human airway epithelium. Proc Natl Acad Sci 106: 12771-12775. doi:10.1073/pnas.0906850106

Rock JR, Onaitis MW, Rawlins EL, Lu Y, Clark CP, Xue Y, Randell SH, Hogan BLM. 2009b. Basal cells as stem cells of the mouse trachea and human airway epithelium. Proc Nat1 Acad Sci 106: 12771-12775. doi:10.1073/pnas.0906850106

Rock JR, Randell SH, Hogan BL. 2010. Airway basal stem cells: a perspective on their roles in epithelial homeostasis and remodeling. Dis Model Mech 3: 545-556. doi:10.1242/dmm. 006031

Rock JR, Gao X, Xue Y, Randell SH, Kong YY, Hogan BL. 2011. Notch-dependent differentiation of adult airway basal stem cells. Cell Stem Cell 8: 639-648. doi:10.1016/j.stem.2011. 04.003

Rodgers JT, King KY, Brett JO, Cromie MJ, Charville GW, Maguire KK, Brunson C, Mastey N, Liu L, Tsai CR, et al. 2014. mTORC1 controls the adaptive transition of quiescent 
stem cells from G0 to G(Alert). Nature 510: 393-396. doi:10.1038/nature 13255

Signer RA, Magee JA, Salic A, Morrison SJ. 2014. Haematopoietic stem cells require a highly regulated protein synthesis rate. Nature 509: 49-54. doi:10.1038/nature 13035

Stabler CT, Morrisey EE. 2017. Developmental pathways in lung regeneration. Cell Tissue Res 367: 677-685. doi:10.1007/ s00441-016-2537-0

Stone KC, Mercer RR, Gehr P, Stockstill B, Crapo JD. 1992. Allometric relationships of cell numbers and size in the mammalian lung. Am J Respir Cell Mol Biol 6: 235-243. doi:10.1165/ ajrcmb/6.2.235

Stripp BR, Maxson K, Mera R, Singh G. 1995. Plasticity of airway cell proliferation and gene expression after acute naphthalene injury. Am I Physiol 269: L791-L799. doi:10.1152/ajplung. 1995.269.6.L791

Tata P, Rajagopal J. 2016. Regulatory circuits and bi-directional signaling between stem cells and their progeny. Cell Stem Cell 19: 686-689. doi:10.1016/j.stem.2016.11.009

Tata PR, Mou H, Pardo-Saganta A, Zhao R, Prabhu M, Law BM, Vinarsky V, Cho JL, Breton S, Sahay A, et al. 2013. Dedifferentiation of committed epithelial cells into stem cells in vivo. Nature 503: 218-223. doi:10.1038/nature12777

Tata A, Kobayashi Y, Chow RD, Tran J, Desai A, Massri AJ, McCord TJ, Gunn MD, Tata PR. 2018. Myoepithelial cells of submucosal glands can function as reserve stem cells to regenerate airways after injury. Cell Stem Cell 22: 668-683 e666. doi:10.1016/j.stem.2018.03.018

Treutlein B, Brownfield DG, Wu AR, Neff NF, Mantalas GL, Espinoza FH, Desai TJ, Krasnow MA, Quake SR. 2014. Reconstructing lineage hierarchies of the distal lung epithelium using singlecell RNA-seq. Nature 509: 371-375. doi: 10.1038/nature13173

Vaughan AE, Brumwell AN, Xi Y, Gotts JE, Brownfield DG, Treutlein B, Tan K, Tan V, Liu FC, Looney MR, et al. 2015. Lineage-negative progenitors mobilize to regenerate lung epithelium after major injury. Nature 517: 621-625. doi:10.1038/ nature 14112

Veldhuizen EJ, Haagsman HP. 2000. Role of pulmonary surfactant components in surface film formation and dynamics. Biochim Biophys Acta 1467: 255-270. doi:10.1016/S0005-2736 (00)00256-X

Volckaert T, Yuan T, Chao CM, Bell H, Sitaula A, Szimmtenings L, El Agha E, Chanda D, Majka S, Bellusci S, et al. 2017. Fgf10hippo epithelial-mesenchymal crosstalk maintains and recruits lung basal stem cells. Dev Cell 43: 48-59 e45. doi: 10.1016/j.devcel.2017.09.003

Wang LD, Wagers AJ. 2011. Dynamic niches in the origination and differentiation of haematopoietic stem cells. Nat Rev Mol Cell Biol 12: 643-655. doi:10.1038/nrm3184

Wang B, Zhao L, Fish M, Logan CY, Nusse R. 2015. Self-renewing diploid Axin2 ${ }^{+}$cells fuel homeostatic renewal of the liver. $\mathrm{Na}$ ture 524: 180-185. doi:10.1038/nature 14863
Watson JK, Rulands S, Wilkinson AC, Wuidart A, Ousset M, Van Keymeulen A, Gottgens B, Blanpain C, Simons BD, Rawlins EL. 2015. Clonal dynamics reveal two distinct populations of basal cells in slow-turnover airway epithelium. Cell Rep 12: 90-101. doi:10.1016/j.celrep.2015.06.011

Webster MT, Manor U, Lippincott-Schwartz J, Fan CM. 2016. Intravital imaging reveals ghost fibers as architectural units guiding myogenic progenitors during regeneration. Cell Stem Cell 18: 243-252. doi:10.1016/j.stem.2015.11.005

Wells JM, Watt FM. 2018. Diverse mechanisms for endogenous regeneration and repair in mammalian organs. Nature 557: 322-328. doi:10.1038/s41586-018-0073-7

Wright JR, Clements JA. 1987. Metabolism and turnover of lung surfactant. Am Rev Respir Dis 136: 426-444. doi:10.1164/ ajrccm/136.2.426

Xi Y, Kim T, Brumwell AN, Driver IH, Wei Y, Tan V, Jackson JR, $\mathrm{Xu}$ J, Lee DK, Gotts JE, et al. 2017. Local lung hypoxia determines epithelial fate decisions during alveolar regeneration. Nat Cell Biol 19: 904-914. doi:10.1038/ncb3580

Xin T, Greco V, Myung P. 2016. Hardwiring stem cell communication through tissue structure. Cell 164: 1212-1225. doi:10.1016/j.cell.2016.02.041

Yang Y, Riccio P, Schotsaert M, Mori M, Lu J, Lee DK, GarcíaSastre A, Xu J, Cardoso WV. 2018. Spatial-temporal lineage restrictions of embryonic $\mathrm{p} 63^{+}$progenitors establish distinct stem cell pools in adult airways. Dev Cell 44: 752-761 e754. doi:10.1016/j.devcel.2018.03.001

Yanger K, Knigin D, Zong Y, Maggs L, Gu G, Akiyama H, Pikarsky E, Stanger BZ. 2014. Adult hepatocytes are generated by self-duplication rather than stem cell differentiation. Cell Stem Cell 15: 340-349. doi:10.1016/j.stem.2014.06.003

Zacharias WJ, Frank DB, Zepp JA, Morley MP, Alkhaleel FA, Kong J, Zhou S, Cantu E, Morrisey EE. 2018. Regeneration of the lung alveolus by an evolutionarily conserved epithelial progenitor. Nature 555: 251-255. doi:10.1038/ nature25786

Zepp JA, Zacharias WJ, Frank DB, Cavanaugh CA, Zhou S, Morley MP, Morrisey EE. 2017. Distinct mesenchymal lineages and niches promote epithelial self-renewal and myofibrogenesis in the lung. Cell 170: 1134-1148 e1110. doi:10.1016/ j.cell.2017.07.034

Zhou B, Flodby P, Luo J, Castillo DR, Liu Y, Yu FX, McConnell A, Varghese B, Li G, Chimge NO, et al. 2018. Claudin-18-mediated YAP activity regulates lung stem and progenitor cell homeostasis and tumorigenesis. I Clin Invest 128: 970-984. doi:10.1172/JCI90429

Zuo W, Zhang T, Wu DZ, Guan SP, Liew AA, Yamamoto Y, Wang X, Lim SJ, Vincent M, Lessard M, et al. 2015. p $63^{+} \mathrm{Krt} 5^{+}$distal airway stem cells are essential for lung regeneration. Nature 517: 616-620. doi:10.1038/nature13903 


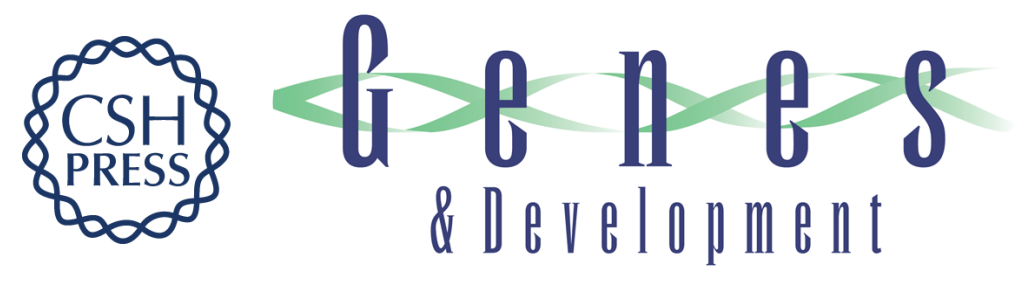

\section{Repairing the lungs one breath at a time: How dedicated or facultative are you?}

John P. Leach and Edward E. Morrisey

Genes Dev. 2018, 32:

Access the most recent version at doi:10.1101/gad.319418.118

References

Creative

Commons

License

Email Alerting
This article cites 86 articles, 12 of which can be accessed free at: http://genesdev.cshlp.org/content/32/23-24/1461.full.html\#ref-list-1

This article is distributed exclusively by Cold Spring Harbor Laboratory Press for the first six months after the full-issue publication date (see

http://genesdev.cshlp.org/site/misc/terms.xhtml). After six months, it is available under a Creative Commons License (Attribution-NonCommercial 4.0 International), as described at http://creativecommons.org/licenses/by-nc/4.0/.

Receive free email alerts when new articles cite this article - sign up in the box at the top right corner of the article or click here.

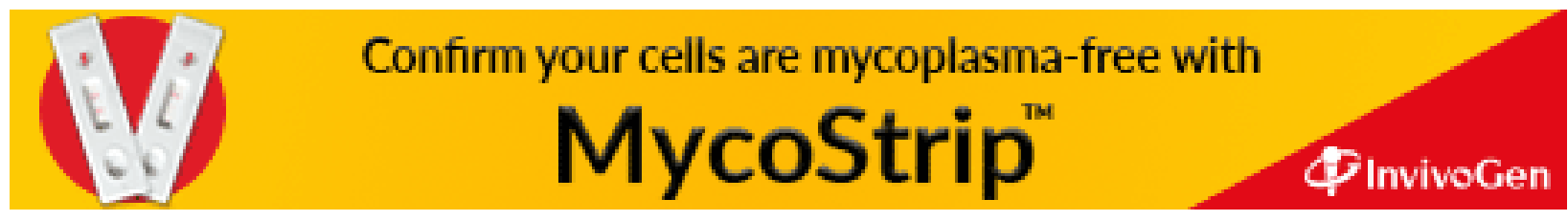

